\title{
El acertijo de la metáfora visual ${ }^{\star}$
}

\author{
Adriana De la Rosa Alzate** \\ Recibido: 2016-04-20. Enviado a pares: 2016-04-29 \\ Aprobado por pares: 2016-05-29. Aceptado: 2016-06-09 \\ DOI: 10.22395/angr.v15n29a8
}

\begin{abstract}
Resumen
En este artículo se presentan los resultados de la investigación sobre el proceso de interpretación de la metáfora visual, en niños entre tres y cuatro años de edad. El propósito de la investigación fue dar cuenta del proceso de interpretación de la metáfora visual y del razonamiento involucrado. La metáfora visual se entiende como un fenómeno en el que los objetos representados presentan transformaciones que traen como consecuencia la emergencia de nuevas categorías e incluso la ambigüedad, es decir, que el objeto pueda pertenecer al mismo tiempo a más de una categoría. Se realizó un estudio de caso con un grupo de ocho niños; es un estudio longitudinal, en el que se hace seguimiento sobre cómo progresivamente acceden a la comprensión de la metáfora. Los resultados permiten afirmar que el proceso de comprensión implica establecer relaciones inferenciales que corresponden con inferencias abductivas. Se identifican seis niveles en la interpretación. En los dos niveles más extremos se encuentra que los niños entienden que es posible que un objeto representado se transforme y, sin embargo, siga perteneciendo a la misma categoría. Por otra parte, el nivel más elaborado es cuando construyen la nueva categoría que emerge en la imagen metafórica. Se establece que las interpenetraciones se comprenden primero en comparación con los tropos icónicos. Los resultados revelan las lecturas elaboradas que los niños hacen, lo que aporta elementos para el diseño de materiales con imágenes de calidad que consideren al niño como un lector cualificado.
\end{abstract}

Palabras clave: metáfora visual, inferencia abductiva, interpretación de la imagen en niños

Este artículo se deriva de la tesis doctoral de la autora. Docente Departamento de Lenguaje. Universidad Autónoma de Occidente. COLOMBIA

.* Universidad Autónoma de Occidente. Doctora en Psicología. Docente Universidad Autónoma de Occidente - Cali. eadelarosa@uao.edu.co 


\title{
Visual Metaphor Guessing Game
}

\begin{abstract}
This article shows the results of a research on visual metaphor interpretation process in children between 3 and 4 years old. The purpose of the research was to state the visual metaphor interpretation process and the involved reasoning. Visual metaphor is understood as a phenomenon in which represented objects show transformations which result in an arising of new categories and even ambiguity, that is to say, that the object may belong to a more than one category, at the same time. A study case was carried out with a group of eight children; it is a longitudinal study, in which there is a follow-up of how they progressively access to the comprehension of the metaphor. Results allow affirming that the comprehension process implies stablishing inferential relations, which correspond to abductive inferences. Six interpretation levels are identified. In the two extreme levels, it was found that children understand that it is possible that a represented objet is transformed and, nevertheless, continues belonging to the same category. On the other hand, the most elaborated level is when the new category is constructed in a way that it emerges I the metaphorical image. It has been established that interpretations are first understood in comparison with iconic tropes. Results show the elaborated readings made by the children, which contributes elements for materials design with quality images, which consider the child as a qualified reader.
\end{abstract}

Key words: visual metaphor, abductive inference, interpretation of an image in children 


\section{Introducción}

La investigación sobre la interpretación de la imagen se enfrenta con diversos obstáculos. Uno de los más fuertes es la aparente facilidad en su interpretación; se cree que las imágenes son transparentes, que no es necesario un esfuerzo por parte del lector porque los elementos saltan a la vista. Sin embargo, los estudios muestran que la idea anterior es una ilusión; por el contrario, objetos como las metáforas visuales son extremadamente complejos, y por esta razón comprometen procesos de razonamiento igualmente elaborados para construir significado a partir de la imagen (Callow, 2006; Everaert, 2003; Seitz, 1997, 1998; Forceville, 2002; Phillips \& Mcquarrie, 2004; Arizpe \& Styles, 2004).

No se discute la primacía de la imagen en la experiencia cotidiana, sin embargo, son escasas las investigaciones que den cuenta de cómo los niños leen las imágenes. Por ello, conocer cómo los niños construyen significado de imágenes complejas como la metáfora aporta a campos cruciales en la actualidad. Su naturaleza insólita como pocos objetos en la experiencia cotidiana promueve formas de razonamiento inferencial que hacen emerger la novedad en el pensamiento del niño y permiten conocer cambios en su funcionamiento inferencial. Establecer los procesos de interpretación de la imagen permitiría atender con más cuidado los múltiples materiales impresos y digitales que están dirigidos a ellos.

El propósito del presente estudio fue rastrear el proceso de interpretación de la metáfora visual en niños entre 3 y 4 años de edad y desvelar el razonamiento que subyace. Sin embargo, antes fue necesario resolver muchos problemas que se encuentran en el camino, para empezar construir una caracterización de la imagen metafórica. La investigación se ha enfrentado al problema de definir y categorizar las clases de imagen, lo cual implica establecer niveles de complejidad.

La metodología es el estudio de caso, que se lleva a cabo a través de un estudio longitudinal que se complementa con series de tiempo; esto significa que las imágenes se presentaron cada quince días, durante seis meses.

En el documento se presenta, en primer lugar, la caracterización de la metáfora visual que orienta la investigación. En segundo lugar, se ahonda en el razonamiento que subyace al proceso de interpretación. A continuación, se ejemplifica con algunas de las respuestas de los niños frente a una de las series de imágenes que se presentaron y se explican las diferencias en el razonamiento que subyace a las interpretaciones. Finalmente, se exponen los indicadores que dan cuenta del cambio en la comprensión y se cierra con algunos casos en los que se evidencia el cambio en la interpretación de la imagen metafórica.

\section{Metáfora visual}

Los estudiosos de la metáfora (Black, 1963; Goodman, 1968; Ricoeur, 1977; Anderson, 1984b) coinciden en que se caracteriza por que recoge simultáneamente dos tópicos distintos que normalmente son excluyentes. Los conceptos en interacción exigen que el lector cree nuevas categorías que eran inexistentes y flexiblemente se mueva entre una 
o más clases. Hay consenso en que la metáfora no se fundamenta en la semejanza; más exactamente, como fenómeno creativo instaura semejanzas entre elementos que antes de su producción no se relacionaban; por ello se puede afirmar que establece relaciones inéditas.

La investigación sobre su comprensión enfrenta el problema de caracterizarla y diferenciarla de otras imágenes; Este ha sido un obstáculo ya que durante más de veinte años se utilizaron imágenes no metafóricas para investigar su comprensión (Kogan et al., 1980, Dent \& Rosenberg, 1990; Seitz, 1997). Las imágenes utilizadas correspondían con lo que en este trabajo se llama imagen convencional. Por el contrario, en la presente investigación la metáfora visual se define porque uno o varios elementos que la componen son incompatibles y generan simultáneamente representaciones de elementos dispares, tal y como sostenía Black en referencia a la metáfora verbal (1963). Su comprensión invita entonces al lector a un ejercicio de integración, en el que se derriban las fronteras entre sus componentes hasta construir una categoría única para esa imagen, y se salva, así, la lejanía que existe entre ellos.

Su interpretación hace posible concebir el estallido de los significados convencionales, derribar las fronteras entre plantas y animales o entre peces y aves, entre zanahorias y botellas, para construir una categoría que reúna lo que quizá nunca antes el lector había imaginado que se pudiera juntar. La importancia de la metáfora visual está dada por que permite asomarse y conocer las entrañas del razonamiento creativo.

En otras palabras, ella tiene una función fundamental: comprender y producir metáforas es dar un salto conceptual en el que el sujeto puede pensar un asunto bajo una luz distinta, y concebirlo en formas que no había contemplado antes.

Los estudios sobre su comprensión encasillaban las producciones del niño en momentos excluyentes: comprendía o no comprendía, lo cual impidió ver el trabajo laborioso que llevaba a cabo para construir significado. Oscureció, además, los puntos intermedios que permiten asistir a la emergencia de la inferencia abductiva; en otras palabras, a la emergencia del pensamiento creativo.

\section{Clasificación de figuras icónicas}

En el cuadro del grupo miu (u, 1993: 160; Klinkenberg, 1996, 2006) se proponen dos oposiciones que dan lugar a cuatro categorías (presencia, in absentia, conjunción y disyunción), para sistematizar las figuras icónicas.

Cuadro 1. Clasificación de las figuras icónicas

\begin{tabular}{|l|l|l|}
\hline & \multicolumn{1}{|c|}{ Conjunción } & \multicolumn{1}{c|}{ Disyunción } \\
\hline In praesentia & interpenetraciones & Acoplamientos \\
\hline In absentia & Tropos icónicos & Tropos proyectados \\
\hline
\end{tabular}




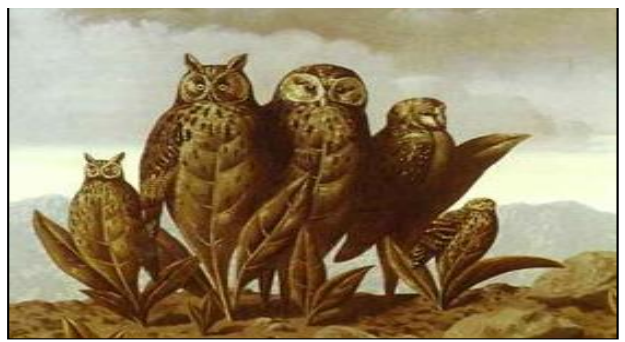

Imagen 1.

1. El modo in praesentia conjunto (IPC) Interpenetraciones: "Las dos entidades están conjuntas en un mismo lugar, pero con sustitución parcial solamente" (grupo miu, u, 1993, p. 160). Los límites entre las entidades son imprecisos, no se sabe muy bien dónde empieza uno y termina el otro. Este es el caso de la imagen adjunta "Los compañeros del miedo" de René Magritte. El cuerpo de los búhos es al mismo tiempo las hojas de las plantas. Estas figuras son denominadas por el grupo miu (u, 1993) interpenetraciones.

2. El modo in absentia conjunto (IAC) tropos icónicos: "Las dos entidades son conjuntas, es decir, ocupan el mismo lugar del enunciado por substitución total del uno por el otro" (grupo miu, u, 1993, p. 245).

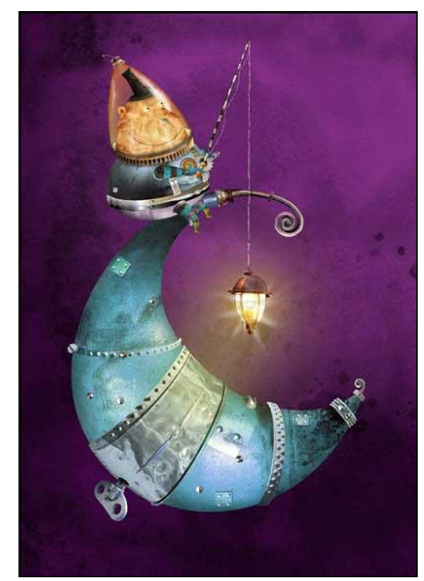

Imagen 2.

En la imagen adjunta del ilustrador Pablo Bernasconi, sobre una luna compuesta por materiales metálicos y corrugados y un mecanismo de cuerda, aparece un personaje con un vestido similar a un astronauta. La luna y la oscuridad que se logra con los tonos oscuros simulan un paisaje espacial. Este personaje trae en la mano una lámpara que pende de un hilo a manera de una caña de pescar, que lleva a pensar en un pescador. El pescador está ausente, pues ha sido sustituido por el astronauta quien está presente. Sin embargo, este último parece llevar a cabo la tarea de pesca en el espacio, lo que entra en conflicto con el lugar habitual en el que se pesca. El anzuelo 
lámpara hace qué surja la inquietud sobre la clase de objetos que se pueden pescar con él.

Si se compara la interpenetración con el tropo icónico se observa que estas imágenes se diferencian por el manejo de las continuidades y discontinuidades: mientras en la planta de lechuzas prima la conjunción y no se sabe muy bien dónde empieza una y dónde termina la otra, en la del astronauta, el pescador aparece sugerido solamente por la caña-lámpara.

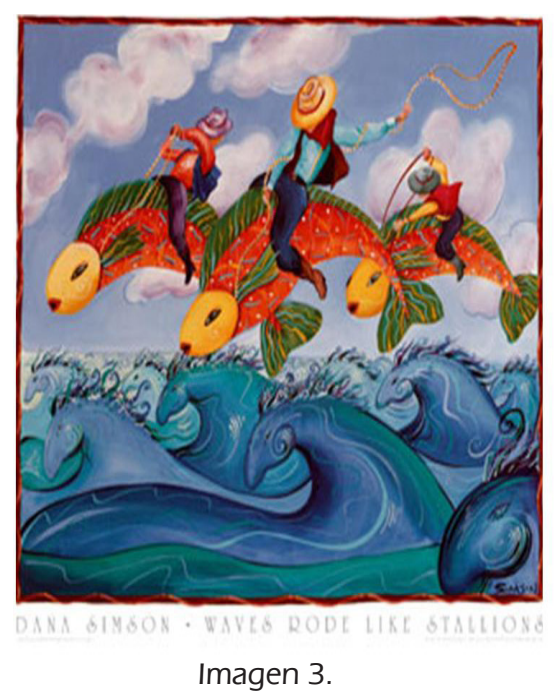

3. El modo in praesentia disyunto (IPD) Acoplamientos: "Las dos entidades ocupan lugares diferentes sin substitución... dos entidades disyuntas pueden ser percibidas como teniendo entre ellas una relación de similitud" (grupo miu, u, 1993, p. 245).

Un ejemplo de acoplamiento es el que se aprecia en la imagen elaborada por Diana Simson. Las olas y las cabezas de los caballos aparecen simultáneamente en distintos lugares, las figuras son fácilmente reconocibles. La transformación se opera en las formas de las olas y en la reiteración del movimiento, los jinetes que cabalgan sobre los peces que, a su vez, cabalgan sobre las olas. Las distintas formas aparecen disyuntas.

4. El modo in absentia disyunto (IAD) tropos proyectados: "una sola entidad es manifestada y la otra es exterior al enunciado, pero proyectada sobre este" (grupo miu, u, 1993, p. 245).

En síntesis, la metáfora visual, de acuerdo con el grupo miu (u, 1993), involucra identificar las relaciones entre la presencia o ausencia de elementos, las adjunciones, conjunciones, disyunciones y supresiones. En todas estas operaciones retóricas entra en juego el dominio del ilustrador, del artista para producir determinados efectos en la imagen. 


\section{La interpretación de la metáfora visual: las fronteras desdibujadas}

Dada la naturaleza de la metáfora, constituida por dos representaciones simultáneas y disímiles (Black, 1963, Ricoeur, 1977), son múltiples los interrogantes que surgen: ¿cómo enfrenta el niño esta incompatibilidad? ¿Cómo construye la unidad? Una explicación es que él puede rechazar, descartar alguno de los elementos que la conforman. O es posible que la construcción de significado se explique por reunir los elementos disímiles ¿Cuál es la naturaleza del significado que construye el niño? ¿Qué forma de razonamiento permite integrar elementos incompatibles? ¿Cómo establecer que ha comprendido la metáfora?

Su comprensión implica reconocer los indicios presentes que remiten a elementos ausentes, registrar estas huellas, pensar las imágenes sin transformaciones y compararlas con las transformadas y dar cuenta de lo que media entre una y otra. El niño logra la síntesis a través de la construcción de una categoría que él no sabía que existía; sin embargo, no se trata de una categoría arbitraria, pues esta guarda relación con los elementos implícitos y explícitos de la imagen.

Esta clase de representación muestra que puede "ver en la mente", manejar representaciones simultáneas, según las cuales lo que ve se parece a unos objetos originalmente sin trasgresiones y reconocer los rastros de estos objetos. Han de representarse al mismo tiempo diferentes versiones de la imagen sin que esto dé lugar al conflicto, según el cual alguno de los objetos representados se rechace o se descarte. La operación que es la base de la comprensión de la metáfora, que implica el salto de establecer relaciones y derivar una categoría híbrida, es la inferencia abductiva.

\section{La abducción: ver en la mente lo que no se ve en la imagen}

La hipótesis de trabajo de esta investigación es precisamente que la comprensión de la metáfora se realiza a través de un proceso de integración, de síntesis en el que se ve lo que no se ve, lo que Peirce llamó la inferencia abductiva, "juntar lo que nunca antes habíamos soñado juntar". ¿De qué otra manera se puede concebir una imagen de una planta de lechuzas? El propósito es rastrear la forma como el niño, a partir de lo que la metáfora visual sugiere, puede ver y construir en su mente la unidad, para lo cual ha de integrar los elementos disímiles.

En este texto se retoma la conceptualización de abducción en Peirce después de 1903, cuando reformula esta inferencia. Las tres clases de inferencias, inductiva, deductiva y abductiva están relacionadas y corresponden a tres etapas de la investigación científica. A través de ellas explica el método científico: "La abducción es el paso en el que se formula una hipótesis a partir de los hechos es lo que llamo el primer estadio de una investigación" (CP 7.203, c. 1901).

\section{Metodología}

En la metodología se combina estudio de casos con una metodología micro genética, que se complementa con series de tiempo. Los estudios de caso se toman en un sentido más 
amplio, dado que el número de sujetos es mayor que el usual en esta clase de estudios (8 sujetos). Se recurre a la metodología micro genética que exige la presentación intensiva de la situación, en períodos cortos de tiempo, en momentos que por estudios previos se han identificado de cambio en la comprensión.

El diseño en series de tiempo se trabaja a lo largo de un seguimiento de 6 meses. El diseño metodológico busca caracterizar los niveles de comprensión de la imagen metafórica, a través de la configuración de las trayectorias del funcionamiento inferencial de los sujetos. Los datos recogidos se componen de la elección de la imagen que presenta cambios más notables y la justificación verbal que hace el niño de la imagen elegida. La elección y la producción verbal permiten determinar el nivel de comprensión de la metáfora visual (ver cuadro 2 sobre comprensión de la imagen metafórica).

El presente estudio se llevó a cabo a lo largo de 6 meses, desde enero hasta junio del 2010, con un grupo de 8 niños. El diseño corresponde a series de tiempo, ya que se hizo un seguimiento a través de la presentación de las imágenes cada quince días, para un total de 12 sesiones en promedio por niño.

\section{Población}

La población de estudio estaba conformada por 8 niños con edades entre 3 años, 3 meses y 4 años. Se seleccionaron niños en estas edades porque por estudios previos se sabe que antes de los 3 años no comprenden la metáfora (Puche, 2001, 2002, 2004). Son momentos de cambios rápidos en dominios específicos; en este caso, se presentan cambios importantes en el razonamiento en relación con las imágenes metafóricas.

En cada presentación se recogieron cuatro elecciones; en los 6 meses se obtuvieron entre 33 y 48 datos por sujeto. El corpus de metáforas se compone de tres imágenes por pantalla, en cada sesión se le muestran cuatro pantallas (4 series de tres imágenes). Se presentaron 3 versiones distintas de imágenes metafóricas para descartar un efecto de memoria o repetición, ya que el niño vería cada versión a las 3 semanas.

\section{Estructura de la tarea}

Al niño se le presenta una primera serie de tres imágenes iguales (tres zapatos, lunas, pájaros, etc.) en pantalla de computador. A los 10 segundos las imágenes se reemplazan por una segunda serie de tres, en la que se rompe la igualdad de la primera serie; en esta última hay dos imágenes que cambian y una permanece exactamente igual que en la primera pantalla.

Él debe darse cuenta de que en la segunda serie, dos de las imágenes cambiaron; debe reconocer que uno de los objetos representados tuvo cambios en sus características: color, forma, posición. Una tercera imagen (la metáfora) tiene cambios tan importantes que aparecen elementos que no le corresponden y que evocan un segundo elemento ausente (lápiz arbóreo, planta de lechuzas, zapatos humanizados); estas presencias son 
tan perturbadoras que el objeto cambia de categoría, deja de pertenecer y en forma más rotunda ya no será más un pez, un pájaro, una lechuza o un lápiz.

La composición de la serie de tres imágenes busca que el niño las compare por sus características, dos no metafóricas y una metáfora. Él ha de identificar en qué consisten estos cambios. Ante la segunda serie se le pregunta: ¿̇uál es la imagen que más se transformó? El niño debía elegir en cada pantalla la imagen que cumpliera con este criterio.

Seguidamente se analizan las respuestas que surgen a partir de la serie de tres imágenes en las que se incluye la metáfora "El modelo rojo" de Magritte.

\section{Resultados}

En este apartado se describen algunas de las series de imágenes utilizadas en el estudio. Posteriormente, se presentan los niveles de interpretación de la metáfora que se construyeron a partir de las respuestas de los niños. Seguidamente se ejemplifican estos niveles con respuestas de los niños frente a la serie de botas, las cuales se representan a través del programa cuadrículas de espacio de estado (state space grids) y finalmente, se ejemplifica con la trayectoria de un niño que revela cómo se da el cambio en la interpretación de la metáfora.

\section{La misma imagen diferentes interpretaciones}

En este apartado se mostrará que una misma serie de imágenes suscita diferentes interpretaciones en los niños, lo que indica que los procesos de razonamiento que le subyacen son igualmente diferentes. Más adelante se mostrará en qué difieren.

En unos casos los niños se centran en las características del objeto representado (color, tamaño, posición); esta clase de razonamiento impide interpretar la metáfora ya que no acceden a la identificación de la trasgresión del objeto ni ponen en juego un análisis y razonamiento en el que se establezcan las relaciones novedosas. Tampoco logran inferir que la trasgresión trae como consecuencia que el objeto cambie de categoría, y dé lugar a la emergencia de categorías sorprendentes e inexistentes, por ejemplo, unas botas humanizadas.

En seguida se mostrará la primera serie de imágenes de la versión n. 3 de imágenes metafóricas. Se ilustrará con algunas respuestas de los niños frente a las imágenes que se les presentaron. En la primera pantalla vieron la imagen de las botas que están a continuación: 

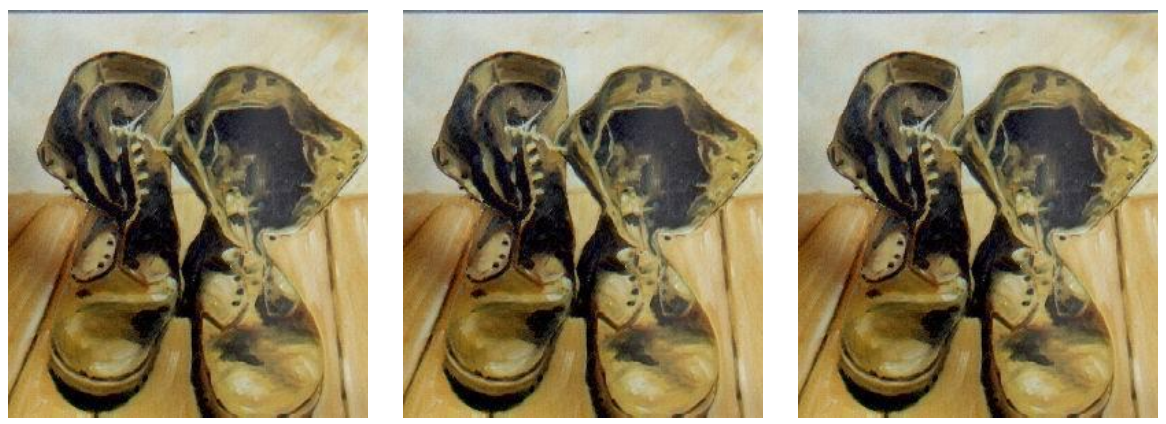

La primera serie de transición se compone de tres imágenes iguales, elaboradas con una técnica de óleo en la que predominan colores cafés y ocres. La imagen se encuentra en una perspectiva frontal que ocupa casi el $90 \%$ del recuadro, sobre un piso de madera en el que se aprecian dos líneas a los lados de las botas, que marcan los límites entre las tablas de madera. La relación figura fondo está dada por los cambios de color, ya que en la mitad, el límite entre el piso de madera y la pared posterior se establece por el cambio entre el café de la madera y el color gris con breves trazos de café de la pared. El contraste claro oscuro se ve en el café oscuro en el interior de las botas y los tonos con algunos visos de luces marcados en el piso, en la parte anterior de las botas y la pared.

Después de las botas los niños cambiaban las imágenes haciendo clic con el mouse y se les advertía que algunas de las imágenes se iban a transformar, ellos vieron las siguientes imágenes. Este ejercicio implicaba que relacionaran la primera serie de tres botas iguales, con la siguiente en la que las botas tenían dos clases de transformaciones: unas con cambios en características y posición, botas negras que aparecen en una perspectiva lateral y la tercera imagen es la pintura de Magritte "el modelo rojo". Esta pintura es desconcertante porque no se sabe muy bien qué es, puede ser una ilusión óptica, o quizá unas botas humanizadas. La pintura de Magritte es, sin lugar a dudas, una metáfora visual, ya que los cambios que se presentan tienen como consecuencia que el objeto representado no se ubique en una categoría definida y, además, es inexistente por fuera de la pintura.


En la imagen de Magritte al igual que las botas sin cambios (no las llamamos literales porque no lo son), la técnica utilizada es el óleo, también predominan colores café y ocre. La profundidad está marcada por el color y la textura. El piso está constituido por material 
pedregoso que se diferencia de la pared que está en la parte posterior porque tiene un color más claro. Además, la pared se compone de las líneas horizontales características de la madera. Las botas están ubicadas lateralmente y ocupan la tercera parte inferior del recuadro. Hay un contraste de luces y sombras ya que en la parte anterior se aprecia un rayo de luz que hace posible ver los detalles de la forma de los dedos, con características como venas en la parte lateral del pie. Los pies van casi hasta la mitad, la transformación de pies en botas está marcada por cambios de color y de iluminación, puesto que el café es más oscuro en la parte que corresponde a las botas. La parte superior se encuentra menos iluminada, se aprecia la textura distinta a la de la piel, a lo que se añade el detalle de los cordones y se nota la presencia de luz en la parte superior de las botas.

\section{¿Cómo ven los niños la serie de botas?}

A los ojos del adulto, si se indaga por la imagen que más se transformó, parece evidente que la pintura de Magritte sería la respuesta indiscutible, se puede pensar incluso que esta elección no implica ningún esfuerzo cognitivo. Pero, en los niños esta no es necesariamente la respuesta correcta. Veremos las respuestas que dan y trataremos de explicar las diferencias y cómo ellas indican diferentes formas de razonar frente a la imagen.

A continuación, en el cuadro 2 se presentan los niveles de interpretación de la metáfora que se derivan del análisis de los datos recogidos en el seguimiento de las respuestas de los niños:

Cuadro 2. Niveles de interpretación de la metáfora visual

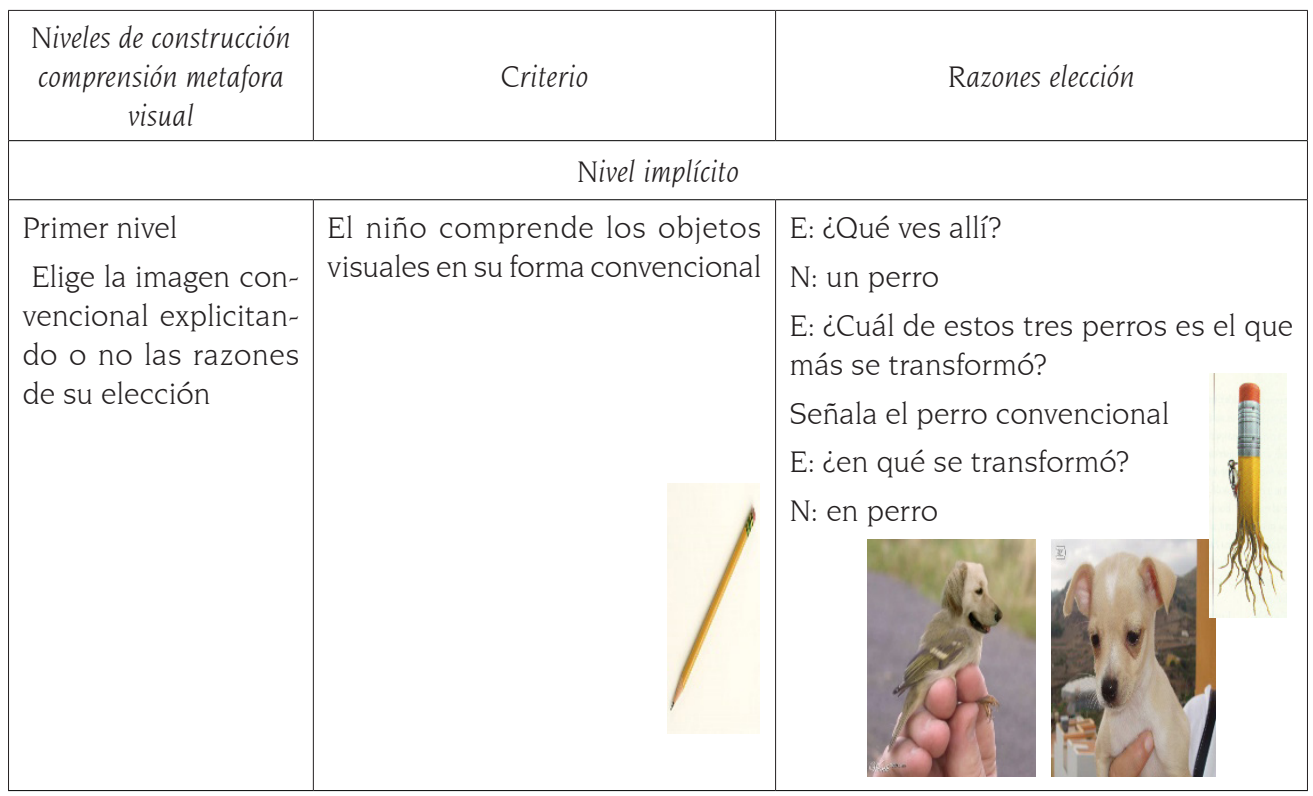




\begin{tabular}{|c|c|c|}
\hline $\begin{array}{c}\text { Niveles de construcción } \\
\text { comprensión metafora } \\
\text { visual }\end{array}$ & Criterio & Razones elección \\
\hline \multicolumn{3}{|c|}{ Nivel implícito } \\
\hline $\begin{array}{l}\text { Segundo nivel } \\
\text { Elige la imagen con- } \\
\text { vencional y da razo- } \\
\text { nes que apelan a los } \\
\text { cambios en el objeto } \\
\text { representado }\end{array}$ & $\begin{array}{l}\text { Predomina la comprensión de } \\
\text { los objetos visuales en su forma } \\
\text { convencional, que se eviden- } \\
\text { cia en la elección de imágenes } \\
\text { convencionales. Aunque puede } \\
\text { identificary explicitar verbalmente } \\
\text { transformaciones en la imagen, } \\
\text { estas no se integran al objeto } \\
\text { representado. }\end{array}$ & $\begin{array}{l}\text { En el siguiente intercambio, J. J., ante la } \\
\text { serie de lápices } \\
\text { E: ¿qué ves? } \\
\text { N: lápices } \\
\text { N: un La... un borrador, de } \\
\text { girar y una casa para pintar y } \\
\text { un lápiz para escribir } \\
\text { E: ¿cuál es el lápiz que más } \\
\text { se transformó? } \\
\text { N: Estos no son lápices (señala el lápiz } \\
\text { arbóreo y el lápiz con dos borradores) } \\
\text { Elige el lápiz convencional } \\
\text { E: ¿̇este antes qué era? } \\
\text { N: un lápiz borrador }\end{array}$ \\
\hline \multicolumn{3}{|c|}{ Nivel transicional } \\
\hline $\begin{array}{l}\text { Tercer nivel } \\
\text { Elige imagen con } \\
\text { cambios en propie- } \\
\text { dades funcionales, } \\
\text { explicitando o no las } \\
\text { razones de su elec- } \\
\text { ción }\end{array}$ & $\begin{array}{l}\text { El niño comprende transformacio- } \\
\text { nes derivadas de las propiedades } \\
\text { funcionales: color, tamaño, po- } \\
\text { sición e incluso de perspectiva. } \\
\text { A diferencia del nivel anterior en el } \\
\text { que predomina la representación } \\
\text { del objeto convencional, en este } \\
\text { segundo nivel el niño infiere las } \\
\text { relaciones entre imágenes y reco- } \\
\text { noce los cambios en las caracte- } \\
\text { rísticas del objeto representado. }\end{array}$ & $\begin{array}{l}\text { M. G., el } 1 \text { de marzo dice que el caballo } \\
\text { se transformó porque tiene "el cabello } \\
\text { largo". } \\
\text { E: ¿En qué se transformó? } \\
\text { Na: en un caballo con pelo largo } \\
\text { E: ¿Antes qué era? }\end{array}$ \\
\hline
\end{tabular}




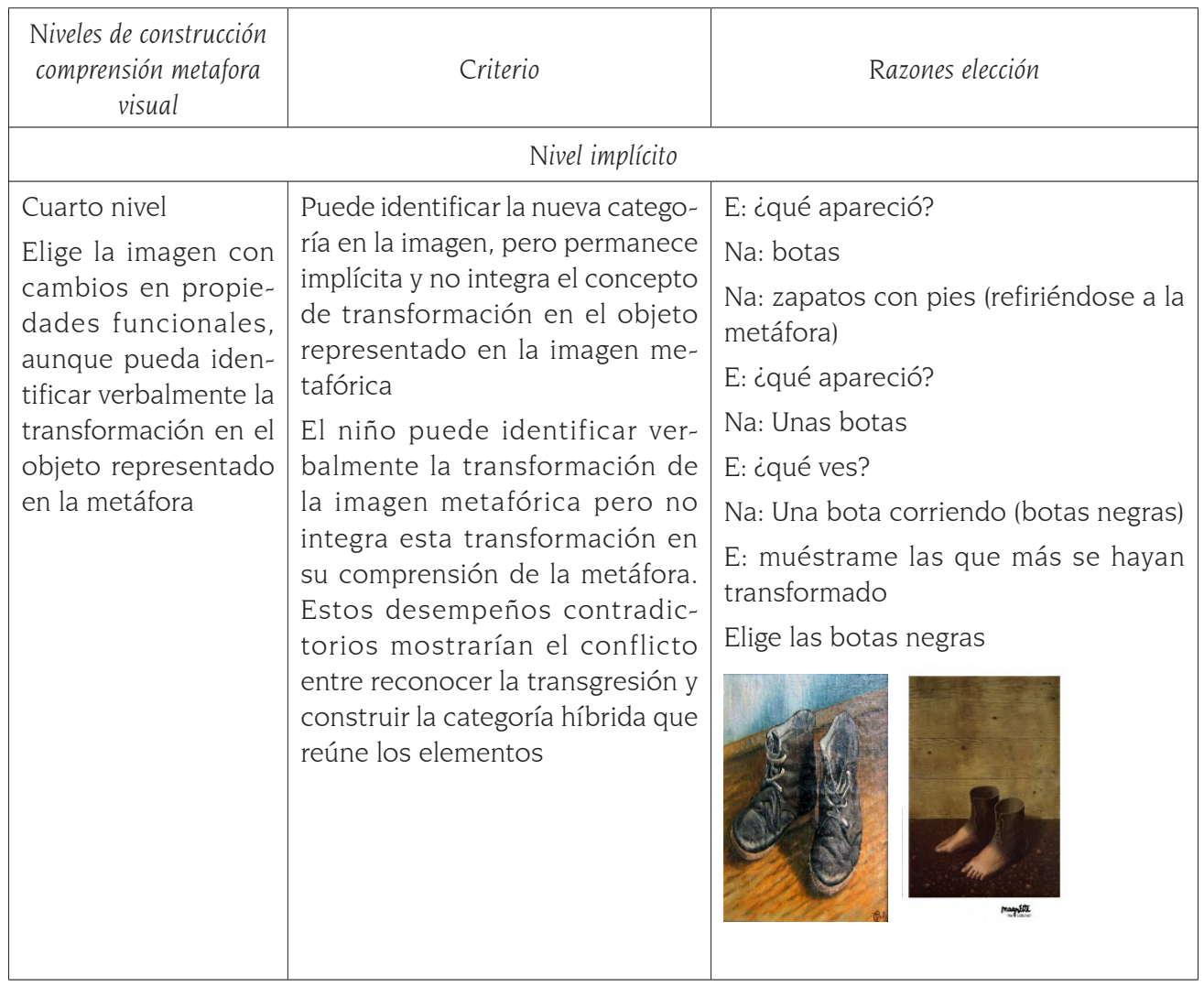




\begin{tabular}{|c|c|c|}
\hline $\begin{array}{c}\text { Niveles de construcción } \\
\text { comprensión metafora } \\
\text { visual }\end{array}$ & Criterio & Razones elección \\
\hline \multicolumn{3}{|c|}{ Nivel implícito } \\
\hline $\begin{array}{l}\text { Quinto nivel } \\
\text { Elige la imagen meta- } \\
\text { fórica sin explicitar en } \\
\text { qué se transformó el } \\
\text { objeto representado. } \\
\text { Apela a la categoría } \\
\text { de la imagen conven- } \\
\text { cional o a las propie- } \\
\text { dades funcionales del } \\
\text { objeto representado }\end{array}$ & $\begin{array}{l}\text { Elige la imagen metafórica, lo que } \\
\text { indica que el niño compara los } \\
\text { objetos representados entre si y } \\
\text { decide que el objeto representado } \\
\text { en la metáfora presenta la trans- } \\
\text { formación más clara. } \\
\text { Aunque elige la metáfora hay } \\
\text { conflicto entre su elección y las } \\
\text { razones que da, ya que apela } \\
\text { al objeto convencional o a sus } \\
\text { propiedades para fundamentar } \\
\text { su elección. }\end{array}$ & $\begin{array}{l}\text { S. M. El } 12 \text { de mayo ante la serie de } \\
\text { búhos: } \\
\text { E: ¿̇ué apareció? } \\
\text { Na: no sé } \\
\text { Na: búhos (planta) } \\
\text { E: ¿cuáles son los que están más trans- } \\
\text { formados? } \\
\text { Señala la planta de lechuzas } \\
\text { E: ¿en qué se convirtieron? } \\
\text { Na: (silencio) no sé } \\
\text { S. L. el } 17 \text { de marzo ante la serie de } \\
\text { imágenes } \\
\text { E: ¿̇qué ves? } \\
\text { N: unos pingüinos de nieves } \\
\text { E: ¿cuáles de estos pájaros son los que } \\
\text { más se transformaron? } \\
\text { Elige la planta de pájaros } \\
\text { E: ¿en qué se transformaron? } \\
\text { N: En unos pájaros }\end{array}$ \\
\hline \multicolumn{3}{|c|}{ Nivel explícito } \\
\hline $\begin{array}{l}\text { Sexto nivel } \\
\text { Elige la imagen me- } \\
\text { tafórica y explicita } \\
\text { las razones de su } \\
\text { elección, identifica la } \\
\text { transgresión o alude } \\
\text { a una categoría sin } \\
\text { correspondencia con } \\
\text { la imagen }\end{array}$ & & $\begin{array}{l}\text { S.H. en la quinta aplicación, ante la } \\
\text { serie de búhos } \\
\text { Na: búhos } \\
\text { Na: ¿esto qué será? } \\
\text { E: ¿a qué se te parece? } \\
\text { Na: un águila } \\
\text { Na: esto un búho } \\
\text { Na: búho también } \\
\text { E: ¿cuál es el que más se transformó? }\end{array}$ \\
\hline
\end{tabular}




\begin{tabular}{|c|c|c|}
\hline $\begin{array}{c}\text { Niveles de construcción } \\
\text { comprensión metafora } \\
\text { visual }\end{array}$ & Criterio & Razones elección \\
\hline \multicolumn{3}{|c|}{ Nivel implícito } \\
\hline & & $\begin{array}{l}\text { Elige la planta de búhos } \\
\text { E: ¿̇en qué se transformó? } \\
\text { Na: en mico }\end{array}$ \\
\hline $\begin{array}{l}\text { Séptimo nivel } \\
\text { Elige la imagen me- } \\
\text { tafórica y hace la in- } \\
\text { ferencia abductiva } \\
\text { que se evidencia en } \\
\text { el establecimiento } \\
\text { de relaciones entre } \\
\text { objetos disímiles y } \\
\text { la creación de una } \\
\text { nueva categoría que } \\
\text { los reúne y que guar- } \\
\text { da relación con los } \\
\text { elementos presentes } \\
\text { en la imagen. }\end{array}$ & & $\begin{array}{l}\text { S. H. ante la serie de botas, el } \\
\text { Na: zapatos } \\
\text { Na: pies con zapatos adentro (se ríe) } \\
\text { Na: Zapatos (sin cambios) } \\
\text { Na: más zapatos } \\
\text { E: ¿cuáles de estos zapatos se transfor- } \\
\text { maron mucho? } \\
\text { Elige los botines de Magritte }\end{array}$ \\
\hline
\end{tabular}

El primero y el segundo niveles de comprensión forman parte del nivel implícito que se caracteriza porque el niño elige la imagen convencional y la justificación verbal ratifica este carácter ("el pájaro se transformó en un pájaro").

El tercero y el cuarto niveles forman parte del nivel transicional; el niño elige la imagen con cambios en características (el caballo se transformó porque ahora tiene el cabello largo y antes lo tenía corto). Habría algunos indicios en los que empieza a considerar cambios, pero estos significados aún permanecen separados y no se arriesga a reunir elementos disímiles en una categoría híbrida.

El nivel explícito incluye los niveles cinco, seis y siete; el límite demarcatorio de este nivel es la elección de la imagen metafórica, que corresponde al quinto nivel. Aunque se 
elija la metáfora su justificación verbal no da cuenta de la categoría híbrida, ya que justifica su elección manteniendo el objeto en la categoría original (se transformó en pez), o a sus propiedades "es un pez grande". Esta actuación contradictoria lleva a preguntarse: ¿por qué ver la metáfora no garantiza "ver" y poder pensar la categoría híbrida? Más adelante se reconstruirá el camino que recorre el niño para construirla.

El séptimo nivel o nivel explícito de comprensión corresponde a la lectura más elaborada de la metáfora, determinado por la elección de la imagen metafórica y la justificación verbal de la elección, que da cuenta de su carácter híbrido: "pies, también son un poquito botas", "el cerdo pirata".

Es necesario advertir que elegir la metáfora no es condición suficiente para sostener que el niño ya la comprende; aún ha de continuar un camino de elaboración de la nueva categoría híbrida que la caracteriza, lo que implica admitir la posibilidad de la integración de elementos disímiles.

\section{Las botas se transforman en botas}

En este punto se mostrará la respuesta inesperada que da una niña, A. H., de 3 años, 9 meses, el 10 de noviembre. En la tercera entrevista selecciona la imagen de las botas sin cambios y justifica su elección de la siguiente manera:

E: ¿qué apareció?

Na: unas botas

Na: unos pies (metáfora)

E: ¿̇y allí?

Na: unas botas

E: ¿qué ves?

Na: unos zapatos

E: muéstrame las botas que más se transformaron

Señala las botas sin cambios

E: ¿en qué cambiaron?

Na: en botas

E: ¿antes qué eran?

Na: botas

Como se puede observar en el diálogo anterior, la respuesta de la niña a la pregunta en qué cambiaron las botas es: "en botas" y no duda cuando se le contra pregunta ¿qué 
eran antes? responde sin titubear manteniendo el elemento en la misma categoría: "en botas", lo que lleva a deducir que ella interpreta que la transformación del objeto representado no quiere decir que cambie de categoría, deje de ser lo que era; por paradójico que parezca, para la niña el objeto se transforma para seguir siendo el mismo.

\section{Tercer nivel de interpretación: cambios en características}

Son distintas las razones que dan los niños para su elección, este es el caso de S. M., niña de 3 años 10 meses, entrevistada el 10 de noviembre quien elige las botas con cambios en características (las botas negras)

E: ¿qué ves?

$\mathrm{Na}$ : Unos zapatos (ante la tríada de botas iguales)

Na: Unos pies

Na: unos zapatos

E: ¿qué ves?

Na: Un zapato

E: ¿cuáles son los zapatos que más cambiaron?

Señala las botas negras

E: ¿en qué cambió?

Na: En un zapato

E: cantes qué era?

Na: Una luna

En el intercambio anterior, cuando se pregunta por los cambios en la imagen seleccionada es curioso que ella denomine la imagen metafórica: "unos pies", los diferencie de las otras dos imágenes: "unos zapatos". Aunque reconoce la imagen diferente, elige los zapatos que cambian de color. Esta elección muestra que la niña compara la primera serie con la segunda, es capaz de admitir cambios en el objeto representado: botas negras con una perspectiva lateral, pero, la representación del objeto aún no admite cambios en la pertenencia a una categoría. A pesar de su elección, verbalmente cambia de categoría al elemento presente en la imagen: "una luna"; los zapatos se transforman en luna pero su respuesta no tiene ninguna correspondencia con las características de la imagen; la transformación que la niña les asigna a los zapatos no se corresponde con ninguna evidencia presente o ausente. Es posible que ella note la contradicción en su respuesta, ya que la imagen elegida no sufrió cambios significativos. Como se puede apreciar la respuesta de S. M. es distinta a la primera respuesta de A. H. para quien es posible que las botas se transformen y continúen siendo "botas". 


\section{Sexto nivel de interpretación: Las botas se transforman}

En seguida veremos la respuesta de S. P. ante la tríada de botas. S. es una niña de 3,5 meses Los datos que se presentan corresponden con la entrevista n. 3 que se realizó el 10 de noviembre.

E: ¿qué apareció?

Na: un pie (los botines de Magritte)

E: ¿qué apareció?

Na: bota

Na: zapatos (botas negras)

E: ¿Cuál de estas tres botas cambiaron mucho?

Elige los botines de Magritte

E: ¿qué les cambió?

Un pie

E: ¿qué eran antes?

Botas

E: ¿Ahora qué son?

Pies, también son un poquito de botas

En el intercambio anterior se nota que la niña identifica la trasgresión presente en la imagen: "un pie", infiere con claridad las consecuencias, la ambigüedad de este nuevo objeto que se representa. Ella puede interpretar los índices presentes en la imagen, se representa los objetos sin transformaciones (pies y botas) y puede admitir la existencia de un objeto que pueda ser al mismo tiempo: "Pies, también son un poquito de botas".

¿Por qué los niños ven cosas distintas? ¿Cómo razona un niño que es capaz de apreciar que en una imagen aparecen botas que son extremidades humanas? ¿Que una imagen pueda ser al mismo tiempo pies y botas? Los botines de Magritte presentan índices que muestran el conflicto (los dedos que remiten a los pies y los cordones que aluden a las botas). Estas características de la imagen no solo exigen que se construya una categoría, en este caso una categoría inexistente; el razonamiento que pone en juego implica que pueda concebir que lo posible exista. Esta forma de razonamiento tan particular es lo que Peirce (1955) llama inferencia abductiva, una forma de pensar que se da cuando se trata de encontrar explicaciones plausibles para fenómenos extraños y novedosos para los cuales no se tiene una solución a la vista. Además, una segunda condición es que se realiza una síntesis entre la inferencia inductiva (relacionar cordones con botas, dedos con pies) y la inferencia deductiva evidenciada por una nueva categoría que el niño ha de crear y que pone a prueba en la imagen. 
No se representan simultáneamente los objetos antes y después de la transformación; tampoco pueden construir la nueva categoría que emerge con la metáfora; niegan la trasgresión y por ello pueden afirmar que los objetos cambian y siguen siendo iguales. En Resumen, no hacen la abducción que la imagen exige, no admiten la posibilidad de que haya objetos escondidos en otros.

Por el contrario, los niños que interpretan la metáfora piensan sobre las imágenes, pueden ver la transformación no solo en la pantalla sino en su mente; esto es muy importante, las transformaciones se construyen en la mente y no se representan porque estén en la imagen. Reconocen los indicios presentes que remiten a elementos ausentes, pueden registrar estas huellas y hacer la inferencia inductiva para pensar las imágenes sin transformaciones. Además, comparan las imágenes "originales" con las imágenes transformadas. Establecen relaciones entre los elementos que forman parte de la imagen metafórica, admiten la posibilidad de la existencia de una categoría inexistente y en su cabeza "juntan lo que nunca antes habían soñado juntar" para construir la nueva categoría que emerge en la metáfora.

\section{Seguimiento al cambio en la interpretación}

En este apartado se presenta el análisis de las elecciones y de las respuestas verbales de algunos de los niños. La representación se hace a través del programa de cuadrículas de espacios de estado (state space grids, Lewis E Hollenstein, 2006). La herramienta captura la interacción de los elementos que conforman el sistema y rastrea las trayectorias de emergencia de patrones de los fenómenos en estudio; en otras palabras, las transiciones en los desempeños a través del tiempo (Hollenstein $\mathcal{E}$ Lewis 2006), en este caso, los cambios en la interpretación de la metáfora.

En estas dos figuras se representan las respuestas de las dos niñas frente a la pintura de Magritte "El modelo rojo".

En el eje de las x aparecen las opciones de las imágenes: imagen sin cambios (IS), imagen con cambios en propiedades (CP) y metáfora (MT). En el eje de las "y" están las categorías que corresponden a los niveles de interpretación como se presentaron antes. Se registran las cuatro respuestas de las niñas ante las cuatro pantallas de imágenes, lo que hace posible apreciar las diferencias en las interpretaciones. La figura 1, de la izquierda, corresponde a A. H. quien se ubica en el segundo nivel de interpretación porque en la representación que ella hace predomina el objeto sin transformaciones. Por el contrario, en la figura 2 de S. P. se puede ver el nivel más alto en la interpretación, el sexto nivel, en el que se observa que la niña construye la nueva categoría de la imagen metafórica.

Veremos en detalle el significado de las convenciones de la herramienta. En la figura 1 están las respuestas de A. H., el círculo sin relleno en la segunda fila inferior es donde se inicia la secuencia del comportamiento (elecciones y niveles de interpretación); las flechas indican la secuencia de las elecciones. La niña inicia eligiendo una imagen sin cambios en la primera pantalla y justifica verbalmente su elección afirmando que "las botas se trans- 
forman en botas"; luego elige una imagen con cambios en propiedades (IP); esta sesión finaliza con la elección de dos metáforas (MT); en la justificación de sus elecciones persiste en mantener el objeto representado en la misma categoría. Su cuarta y última elección es la más elaborada ya que elige una imagen metafórica y construye una nueva categoría, pero su respuesta no corresponde con los indicios presentes ni ausentes en la imagen.

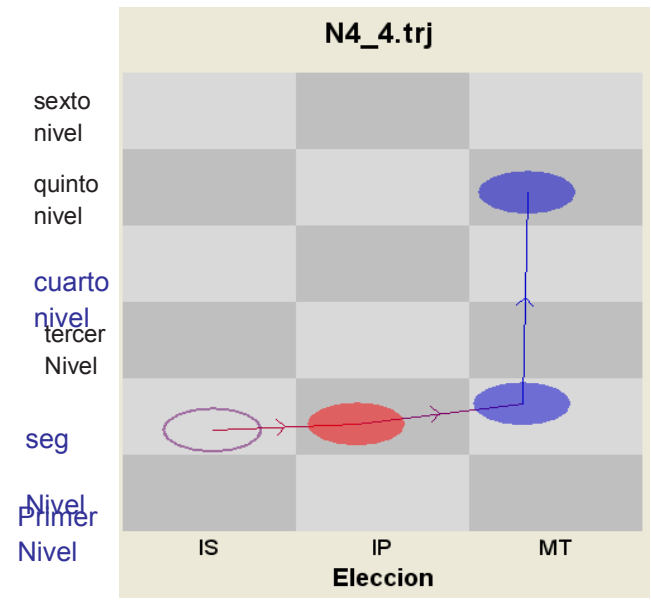

Figura 1

Objeto permanece en la misma categoría

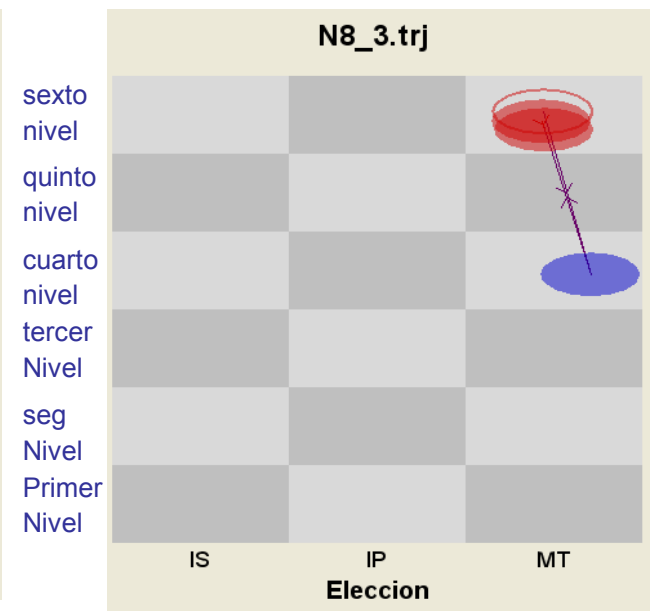

Figura 2

Construye nueva categoría

En la figura 2 están representadas las respuestas de S. P., que se ubican en el cuadrante superior derecho; estas se concentran en los desempeños más complejos que corresponden a la elección predominantemente de metáforas y el reconocimiento de la nueva categoría que emerge: las botas se transforman en pies y "también son un poquito botas" Estas actuaciones se aprecian en los tres círculos que aparecen en la parte superior, solamente hay un círculo azul que se relaciona con la elección de una metáfora y el reconocimiento de la trasgresión presente en ella, sin que dé lugar a la construcción de la nueva categoría.

Veremos enseguida el seguimiento del desempeño de un niño a lo largo de seis meses, desde enero a junio del 2010, en el que se pueden apreciar los cambios en la interpretación de la metáfora visual.

D. T.

Al iniciar las entrevistas D. tiene 3 años, 8 meses, al finalizar su edad es de 4 años, dos meses. Durante las cinco primeras sesiones, en dos meses y medio, como se aprecia en la figura tres, sus elecciones se concentran en la segunda y la tercera filas, que corresponde a selección de imágenes sin cambios o con cambios en propiedades; las justifica 
manteniendo el objeto representado en la misma categoría o apelando a las características del objeto. De los desempeños más bajos, es decir, elección de imágenes sin cambios (figura tres), pasa en la séptima sesión (figura cuatro) a desempeños complejos que dan cuenta de la interpretación de la metáfora. Estos se ubican en la parte superior derecha, ya que elige imágenes metafóricas y, además, justifica sus elecciones haciendo referencia a nuevas categorías, en las que se corrobora la interpretación de la imagen metafórica. El registro en el programa de cuadrículas de espacio de estado hace visible el momento en que el niño cambia su nivel de interpretación.

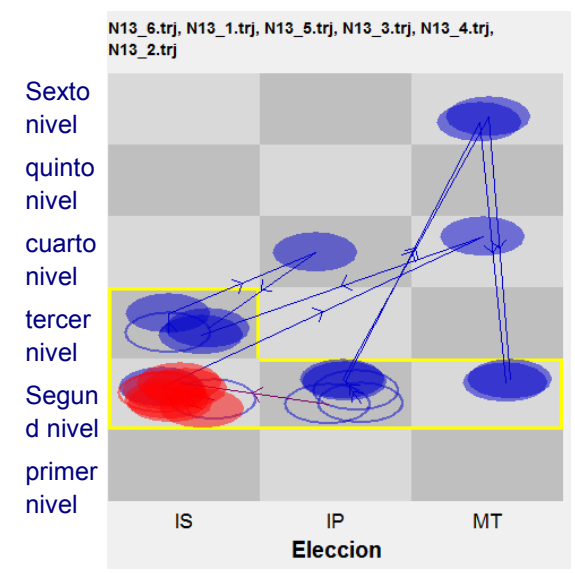

Figura tres.

Sesiones 1 a 6

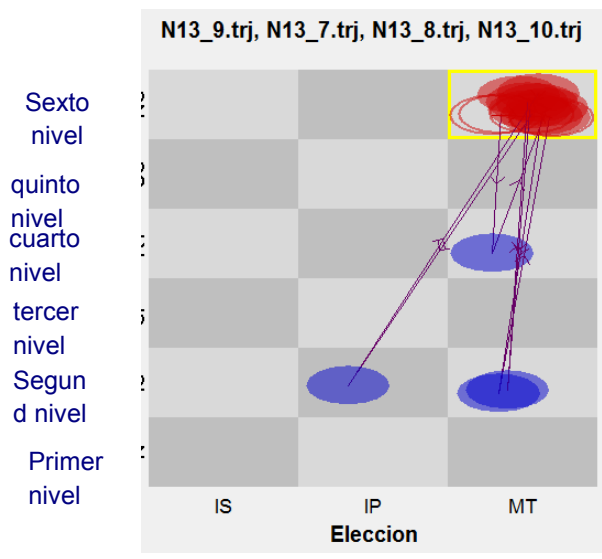

Figura cuatro.

sesiones 7 a 10

Pareciera como si se tratara de un niño distinto. Veamos un ejemplo del cambio en el nivel de interpretación. El 30 de abril ante la serie de imágenes de lápices se presenta el siguiente intercambio:
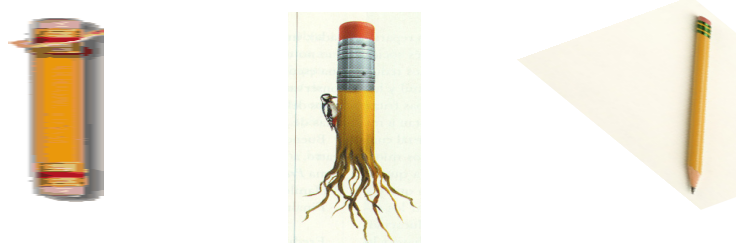

E: cantes qué era?

N: un lápiz

En la sesión del 30 de abril todas sus elecciones son imágenes metafóricas; si se interpretara aisladamente podría pensarse que es una respuesta eventual, sin embargo, 
este mismo desempeño se tiene en las tres sesiones siguientes ante imágenes distintas. Este caso es sorprendente porque los desempeños previos son más sencillos.

No se puede afirmar que la mayoría de los niños va a tener cambios abruptos como D. T.; se trata de la trayectoria de un niño particular. La explicación a estos cambios en los desempeños muestra que inicialmente el niño privilegiaba las similitudes entre los objetos representados en la imagen, es decir, él pensaba en los objetos sin transformaciones y no podía construir el significado una vez estos presentaban trasgresiones. La imagen metafórica no suscitaba el establecimiento de relaciones novedosas ni la síntesis que da lugar a la construcción de la nueva categoría a la que pasa a pertenecer el objeto en la metáfora.

Sus últimos desempeños muestran que cambia el razonamiento sobre la imagen, lo que les permite comparar la representación de los objetos sin transformaciones con los objetos transformados. Además, pueden admitir la emergencia de un objeto novedoso, aunque este no tenga correspondencia con su experiencia.

\section{Conclusiones}

A partir de los resultados se puede plantear la necesidad de estudios longitudinales que puedan dar cuenta de los cambios en la interpretación de la imagen, ya que unas pocas sesiones no son suficientes para dar cuenta de este proceso.

El seguimiento de los cambios en la interpretación de la imagen metafórica muestra el arduo proceso que siguen los niños para interpretar la transformación que se opera en la imagen, lo cual requiere que realice dos comparaciones, la primera, entre la serie inicial de tres imágenes y la segunda serie Por otra parte, en la segunda serie ha de comparar las imágenes entre sí hasta establecer que en solo una de ellas el objeto representado sufre una transformación que va más allá de cambios en características. La interpretación de la metáfora exige la construcción de la nueva categoría que emerge; el niño sabe que la imagen representada deja de ser (caballo, pez, carro) y pasa a formar parte de una nueva categoría, incluso una categoría inexistente (botas humanizadas, cerdo pirata).

Los resultados muestran la presencia del razonamiento inferencial abductivo aún en niños tan pequeños, menores de cuatro años. Esta evidencia lleva a pensar si los materiales con imágenes que se les suelen presentar estarían al nivel del complejo proceso de síntesis que son capaces de realizar.

El niño que interpreta la metáfora supera el momento del desconcierto y razona tan rápidamente que puede crear la nueva categoría que emerge. Es más, puede permanecer en la ambigüedad y pensar al mismo tiempo en diferentes representaciones de la imagen, como decía una niña frente a la metáfora del pez alado (Leo Lionni) "Se parece a muchas cosas". Reconocer la existencia de varias cosas en una sola imagen (pies, un poquito botas), muestra que el niño puede "ver en la mente", maneja representaciones simultáneas según las cuales, lo que ve se parece a unos objetos originalmente sin trasgresiones, puede reconocer los rastros de estos objetos originales, además, inferir que los cambios 
y transformaciones que se operan dan lugar a nuevos objetos. Se produce un salto cualitativo en el razonamiento, los objetos representados dejan de ser lo que eran, "juntan lo que nunca antes habían soñado juntar", razonan e infieren abductivamente para construir la nueva categoría que emerge en la imagen metafórica.

Las diferentes interpretaciones que el niño construye, que se muestran en este trabajo, evidencian que la interpretación de la imagen no es un proceso transparente e inmediato; no es posible sostener que la imagen es un objeto sencillo de descifrar. Ellas muestran que el proceso de aprender a mirar va mucho más allá de pasar los ojos sobre la imagen. Son, por tanto, una prueba contra la idea intuitiva que la apreciación de la imagen es un ejercicio que no demanda un razonamiento complejo.

\section{Referencias bibliográficas}

Arizpe, E. E Styles, M. (2004). Lectura de imágenes: Los niños interpretan textos visuales. Fondo de cultura económica. Primera edición en español, México.

Barrena, S. (2007). La razón creativa: crecimiento y finalidad del ser humano según C. S. Peirce. Ediciones Rialp, Madrid.

Black, M. (1963). Models and metaphors: Studies in language and philosophy. Cornell University press. Ithaca. New York.

Callow, J. (2006). Images, politics and multiliteracies: Using a visual metalanguage.

Tomado de Australian journal of language and literacy, vol. 29, no. 1, 2006, pp. 7-23.

"Deducción, inducción e hipótesis", (1878). Traducción castellana y notas de Juan Martín Ruiz-Werner. En Deducción, inducción e hipótesis, J. Martín Ruiz-Werner (tr., intr. y notas), Aguilar, Buenos Aires, 1970, pp. 65-90.

Dent, C., E Rosenberg, L. (1990). Visual and verbal metaphors: developmental interactions. In Child Development, 61(4), (pp. 983-994).

"El icono, el índice y el símbolo" (c. 1893 1902). Traducción castellana de Sara Barrena (2005). Fuente textual en CP 2.274-308.

Everaert- Desmedt, N. (2003). El guión de Bin Laden: Análisis semiótico de un dibujo en la prensa. En utopía y praxis latinoamericana, 8 (21). Maracaibo.

Everaert-Desmedt, N. (2006), "Peirce's Esthetics", in Louis Hébert (dir.), Signo [on-line], Rimouski (Quebec), http://www.signosemio.com

Forceville, Ch. (2002). The identification of target and source in pictorial metaphors. En journal of pragmatics, 34. 1 14.

Goodman, N. (1968). Languages of art: an approach to a theory of symbols. Edit. The Bobbs Merril Company, Inc. Estados Unidos.

Groupe U (1993). Tratado del signo visual. Ediciones Cátedra. Signo e imagen.

Josephson, J. R., E Josephson, S. (1996). Abductive Inference, Computation, Philosophy, Technology. Cambridge University Press. 
Klinkenberg, J.M. (1996). "precis de semiotique générale". De Boech, Bruxelles.

Klinkenberg, J.M. (2006). Manual de Semiótica general. Editorial Universidad Jorge Tadeo Lozano. Bogotá, Colombia.

Kogan, N.; Connor, K.; Gross, A. \& Fava, D. (1980). Understanding visual metaphor: Developmental and individual differences. Monographs of the society for Research. In Child Development, vol. 45 (1).

Peirce, Ch. S. (1955): "Abduction and induction", en: Peirce, Charles S.Philosophical writings of Peirce, Buchler, Justus (editor) (New York, Dover Publications) pp. 150-156.

Peirce, C. S. (1999). ¿Qué es un signo?”. Traducción castellana de Uxía Rivas Original en CP 2.281, 285 y 297-302. Página Web del Grupo de estudios Peircianos. Universidad de Navarra. España.

"Pragmatism and Abduction" (1903) Collected Papers, C. Hartshorne, P. Weiss y A. W. Burks (Eds.). Cambridge, MA: Harvard University Press, 5.180-211, 1931-1958.

Perner, Josef (1994). Comprender la mente representacional. Ediciones Paidós. España.

Phillips, B. E Mcquarrie, E. (2004). Beyond visual metaphor: A new typology of visual rhetoric in advertising. En Marketing Theory, 4 (1/2), 113-136.

Puche Navarro, R. (2001). Mutaciones, metáforas y humor visual en el niño. In R. Rosas (Ed.). La mente reconsiderada. En homenaje a Angel Riviere (Reconsidered mind. A tribute to Angel Riviére) Santiago de Chile: Spike.

Puche Navarro, R. E Lozano, H. (2002). El sentido del humor en el niño. Estudio empírico (children's sense of humor. An empirical study). Bogotá, Colombia: Siglo del hombre. Editores.

Puche Navarro, R. (2004). Graphic jokes and children's mind: An unusual way of approach to children's representational activity. En Scandinavian journal of psychology, 45, 343-355.

Ricoeur, P. (1977). La metáfora viva. Ediciones Megapolis. Argentina.

Seitz, J. A. (1997). Metaphor, symbolic play, and logical thought. In Early childhood

Genetic, Social, and General Psychology Monographs, v.123 (4), p373. 